\title{
Perception of the Effectiveness of Health-Related Campaigns among the Adult Population: An Analysis of Determinants
}

\author{
Mariusz Duplaga \\ Department of Health Promotion, Institute of Public Health, Faculty of Health Sciences, Jagiellonian University \\ Medical College; 31-008 Kraków; Poland; mariusz.duplaga@uj.edu.pl \\ Received: 4 February 2019; Accepted: 28 February 2019; Published: 4 March 2019

\begin{abstract}
Background: Social campaigns focusing on health are commonly used within an attempt to change behavior. To date, there has not been a targeted analysis of societies' general perception about social campaigns. The aim of this study is to assess citizens' opinions on the effectiveness of health-related social campaigns. Methods: The data set used in the analysis was obtained from Poland's nationwide "Social Diagnosis" study. The determinants of public opinion were assessed using a multivariate logistic regression. The independent variables included socio-demographic characteristics, lifestyle, social participation, and the use of digital media. Results: The logistic regression model was developed using 23,593 cases. Opinions about the effectiveness of campaigns depended on all the predictors included in the socio-demographic cluster, smoking, self-declared excessive alcohol consumption, physical activity, the use of mobile phones, and watching TV. A significant impact was found in all but one variable related to social participation. Conclusions: The analysis revealed that opinions about social campaigns present in the media "landscape" are influenced by many factors. Interestingly, persons exhibiting unhealthy behaviors are more resistant to health-related campaigns and surprisingly the need to make use of healthcare resources is not accompanied by an acceptance of the interventions.
\end{abstract}

Keywords: health promotion; health behaviours; social campaigns

\section{Introduction}

Today, social marketing is perceived as a promising strategy that can lead to health improvement through behavioral change. In 1971, Kotler and Zaltman defined social marketing as "an application of marketing to the solution of social and health problems" [1]. Andreasen also emphasized the importance of social change accomplished through social marketing [2]. It is expected that social marketing employs key elements originating from commercial marketing including consumer research, segmentation, targeting, and an appropriate balance of marketing mix attributes [3]. However, the analysis of the secondary evidence on the use of social marketing strategies in relation to health challenges shows that these requirements are not always strictly addressed [4].

Behavior change was indicated as one of key benchmarks enabling identification of the success of social marketing programs [5]. According to this approach, genuine social marketing programs should use behavior change in both the phase of design and evaluation. Behavior change is also perceived as one of the key aims of health promotion interventions. The epidemiological transformation that occurred in the 20th century resulted in new challenges for public health with non-communicable or chronic diseases becoming one of the main problems. According to a World Health Organization (WHO) Report, eight leading risk factors causing deaths in 2004 included: High blood pressure, smoking, elevated glycaemia, insufficient physical activity, overweight and 
obesity, high cholesterol, risky sexual behavior, and alcohol consumption [6]. These were responsible for $50 \%$ of deaths worldwide [6]. Most of these risks are strongly linked to individual behavior. Therefore, the modification of health behaviors is an essential outcome for a successful health promotion campaign, especially in the context of non-communicable diseases. However, despite many theoretical frameworks for modifying health behaviors [7] and the efforts made to develop effective interventions, the area remains a major challenge in public health $[8,9]$. Some authors stress that interventions focused on changing health behaviors, undertaken in order to reduce alcohol consumption, to prevent obesity or to increase physical activity, have only limited impact on the targeted populations $[9,10]$. A search for new approaches to influence health-related behaviors results from the apparent disillusionment with the existing strategies.

Social marketing, despite many reservations, is a possible approach. The interest in social marketing is based on the recognition that today, lifestyle and health related behaviors are strongly influenced by the overwhelming influence of consumerism and an exposure to commercial marketing. There is growing evidence that the prevalence of chronic diseases is strongly dependent on the consumption of unhealthy products aggressively marketed by the industry [11]. Social marketing, employing similar techniques to those used for commercial marketing, is perceived as an adequate countermeasure.

Furthermore, social marketing is an attractive option for public health campaigns, as it can be used to address many potential objectives; not only shaping individual health behaviors, but also changing attitudes of policy makers and stakeholders who influence the legal environment for health.

The evidence accumulated so far indicates that social marketing techniques may be effective in many key areas for health promotion. Their feasibility was demonstrated in relation to items such as: Youth obesity [12], increasing physical activity among adults [13], addressing global health issues [14], preventing and controlling sexually transmitted diseases [15], distributing health-related products [16], promoting influenza vaccination [17], healthful eating [18], and cessation of smoking [19]. On the other hand, there are also areas of health promotion in which the effectiveness of social marketing techniques was not confirmed [20].

While social marketing programs are usually expected to assume a more comprehensive approach to behavior change, they are frequently limited to campaigns based only on communication interventions. Campaigns utilizing modern communication channels, which are an inherent element of "the landscape" of traditional and digital media have become a popular strategy for delivering health-related messages to society. There are numerous examples of the robust assessment of social campaigns addressing health-related issues such as smoking [21], however, many social campaigns broadcasted by the mass media are not followed by an appropriate evaluation. While techniques of social marketing may be feasible for many health challenges, their use has rarely been assessed in terms of effectiveness or acceptance by the general public.

The primary aim of this study is the assessment of determinants of opinion about the effectiveness of health-related social campaigns by the public. Social marketing has become an important tool for health promotion and disease prevention in Poland. The increased trend of using social marketing accelerated after Poland joined the European Union in 2004, by the ability to use structural funds designed for social change in new member states. Both public institutions and non-governmental organizations began exploring social marketing techniques as a means to promote change in public behaviors and attitudes.

To clarify the perception of health campaigns in Polish society, the dataset of a nationwide study entitled "Social Diagnosis" was explored and relevant data were extracted [22]. A multivariate logistic regression model was developed to determine factors shaping public opinion about the effectiveness of health-related social campaigns. Potential predictor variables were derived from items asking about socio-demographic features, lifestyle, and health status, the use of television (TV), modern technologies, and social participation. 


\section{Materials and Methods}

\subsection{Overview}

The analysis of factors determining public opinion about the effectiveness of health-related social campaigns was carried out from data collected during the wave of the Social Diagnosis study performed in 2011. The "Social Diagnosis" is a panel study carried out every two years on a national sample representative of all Poland [22]. The study is focused primarily on the assessment of objective and subjective quality of life. A two-stage households sampling procedure, based on territorial units and categories of the area of residence was used in the study. Respondents of 16 years and over were asked to fill individual questionnaires in the presence of interviewers employed by the study. The data set from the Social Diagnosis study may be accessed from the website maintained by the research team [23]. The details of the sampling procedure and generation of calibrated weights are specified in the report from the study [24].

\subsection{Dependent Variable}

During the 2011 study, an item asking about the respondent's opinion of the effectiveness of health-related social campaigns was included in the individual questionnaire ("Do you think that social campaigns and other actions aimed at improving health, e.g., antismoking campaigns, campaigns against drugs and promotion of vaccinations, are effective and change people's behaviour in Poland?"). A dependent variable used for logistic regression model development was derived from this item. It was coded as follows: The response options "decidedly yes" and "rather yes" were treated as confirmation of conviction that social campaigns are effective (coded as ' 1 '), and options "decidedly no", "rather no", and "difficult to say" as a lack of conviction about the campaign's effectiveness (coded as ' 0 ').

\subsection{Independent Variables}

Four types of independent variables were used in the multivariate logistic regression model. They included sociodemographic characteristics, variables related to lifestyle and health behaviors, variables related to social participation, and finally, variables reflecting the use of media and information technologies (IT).

\subsection{Sociodemographic and Economic Characteristics}

The cluster of sociodemographic variables consisted of gender, age category, education level, place of residence, marital status, occupational status, and net income. The age of respondent was included as a categorized variable with 6 intervals assumed in the "Social Diagnosis" study: 18-24, 25-34, 35-44, 45-54,55-64, and 65 years or more. Place of residence also was characterized by 6 values: urban areas with >500,000 inhabitants, 200,000-500,000, 100,000-200,000, 20,000-100,000,<20,000 and rural area. Education level was assigned with four options: primary or lower education (level 1 or lower, as classified by the International Standard Classification of Education (ISCED)) [25], lower secondary (vocational education or middle school; level 2 according to ISCED), upper secondary (level 3 according to ISCED), and post-secondary non-tertiary education or university education (levels 4-8 according to ISCED). Marital status assumed four options: 'married', 'unmarried', 'widower/widow', and 'divorced or remaining in separation' (formal or actual). Six categories were used for occupational status: 'employee', 'self-employed or entrepreneur', 'retired or on disability pension', 'university or school student', 'unemployed or occupationally passive', and 'not provided'. The initial continuous variable providing information about the level of personal net monthly income (average from three preceding months) was categorized into four categories: $\leq 1000$ Polish zlotys (PLN), >1000 to 2000, >2000 PLN per month, and 'not provided'. 


\subsection{Use of Health Care Services and Lifestyle}

Use of health care services during the last year was a dichotomous variable coded as ' 0 ', if the respondent used neither public nor private health care services in the preceding year, and as ' 1 ' in cases of at least one episode of use. The variable disability status was derived from the relevant item asking about respondent's being disabled (either formal status when disability was established by decision of a relevant institution in Poland, or informal, when such a confirmation was not sought).

Respondents were asked if they undertake any form of physical activity or sport (no activity vs. at least one type of physical activity or sport). Items asking about current smoking and excessive alcohol consumption were also dichotomous ('no' vs. 'yes'). Finally, the body mass index (BMI) was calculated from weight and height values provided by respondents in the individual questionnaires and categorized by four intervals: $<18.5$ (underweight), $\geq 18.5$ to $<25.0$ (normal weight), $\geq 25$ to $<30.0$ (overweight), and $\geq 30.0$ (obesity).

\subsection{Television (TV) and IT Use}

In this group, three variables were included: computer use, mobile phone use and TV viewing. Computer use and mobile phone use were dichotomous variables ('no' vs. 'yes') The variable related to daily TV viewing assumed four values: Not watching TV, watching TV for less than $1 \mathrm{~h}$, for $1-2 \mathrm{~h}$, and for more than $2 \mathrm{~h}$ daily.

\subsection{Social Participation}

There were six variables related to social participation used in the model: The number of friends with whom a respondent meets regularly, involvement in activities for the local community, membership in social organizations, participation in religious practices, participation in the last election before the survey, and the ability to indicate a political option. The variable related to number of friends declared assumed 4 values: not more than 2, 3-4, 5-9, and more than 9 friends. The variables indicating involvement in activities for benefit of the local community (district, village or city, neighborhood) and membership to social organizations were dichotomous (lack of involvement or membership vs. confirming activity). Participation in religious services or meetings was assessed based on the number of events attended per month. A relevant variable could assume three values: ' 0 ' for those participating in religious services less than once monthly or not participating; ' 1 ' for once monthly and ' 2 ' for at least twice monthly. Political activity was determined from the response asking about active participation in local government elections, which took place in 2010 (the last elections taking place before the 2011 Social Diagnosis study). The variable could assume three values: not participating in elections, declaring participation, and response not provided. Finally, an independent variable was derived from the response asking for indication of a political party that is closest to the respondent's views. It assumed three values; 'no political sympathy', 'difficult to say', and 'clear political sympathy'.

\subsection{Data Analysis}

The analysis was performed with SPSS v.21 for Windows (IBM Corp., Armonk, NY, USA). Only data of respondents of 18 years or over were retrieved for the analysis. The frequencies reported in the paper were provided after exclusion of missing values. The factors that could have impact on the opinion about the effectiveness of health-related social campaigns were included as independent variables in the multivariate logistic regression model. The forward method available in SPSS v.21 package was applied. For each independent variable included in the model, odds ratio (OR), and $95 \%$ confidence interval $(95 \% \mathrm{CI})$ were provided. The logistic regression modelling was preceded with assessment of missing values. As the percentage of missing values was lower than $1 \%$ for all but one independent variable; in the case of computer use, it was $1.3 \%$, and it was decided that all records with at least one missing value would be removed from the model. Thus, the multivariate logistic regression model was calculated, after adjusting for standardized weights. The analysis of 
multicollinearity demonstrated that VIF values for independent variables remained in the interval 1.07-2.07. Therefore, all of them were included in the multivariate logistic regression model.

\section{Results}

\subsection{Characteristics of the Study Group}

Weighted number of respondents was 23.593 persons with women composing $55.92 \%$. The percentage of persons with university education or higher was $19.15 \%$, and those with primary education $18.48 \%$. The number of persons working as employees was $35.29 \%$, self-employed $3.86 \%$, farmers $6.42 \%$, and retired or receiving disability pension $33.29 \%$ of all respondents.

Nearly $82 \%$ of all respondents used private or public health care services at least once in the preceding year. In the study population $14.26 \%$ had disabilities. Only $34.20 \%$ declared some type of physical activity, $6.14 \%$ reported excessive use of alcohol, and $26.28 \%$ smoking. $54.91 \%$ of the respondents were overweight or obese. Computer use was confirmed by $53.35 \%$ of respondents and the use of mobile phone by $81.62 \%$. Only $2.56 \%$ reported that they did not watch TV.

Respondents who had no more than two friends were the most numerous group (32.47\%). Only $15.91 \%$ confirmed involvement in activities for their local communities and $11.62 \%$ reported participation in some type of social organizations. $67.93 \%$ of respondents reportedly participated in local government elections in 2010 and $45.17 \%$ of them indicated political party views close to their own. Finally, 53.35\% of respondents expressed the opinion that health-related social campaigns are effective, while the remaining respondents were not convinced about the effectiveness. Detailed characteristics of the study group are provided in Table 1 (the numbers and frequencies are provided for weighted values).

Table 1. Characteristics of the study population (weighted values).

\begin{tabular}{llll}
\hline Variable & Categories & $\mathbf{n}$ & $\mathbf{\%}$ \\
\hline \multirow{2}{*}{ Gender } & female & 13,193 & 55.92 \\
\cline { 2 - 4 } Age category & male & 10,400 & 44.08 \\
\hline & $18-24$ & 2864 & 12.14 \\
\cline { 2 - 4 } & $25-34$ & 3555 & 15.07 \\
\cline { 2 - 4 } & $35-44$ & 3547 & 15.03 \\
\cline { 2 - 4 } & $45-54$ & 4334 & 18.37 \\
\cline { 2 - 4 } & $55-64$ & 4759 & 20.17 \\
\cline { 2 - 4 } & $>64$ & 4534 & 19.22 \\
\hline \multirow{5}{*}{ Place of residence } & primary education & 4359 & 18.48 \\
\cline { 2 - 4 } & lower secondary education & 7470 & 31.66 \\
\cline { 2 - 4 } & upper secondary education & 7245 & 30.71 \\
\cline { 2 - 4 } & post-secondary non-tertiary education or higher level & 4519 & 19.15 \\
\hline & urban $>500,000$ & 1788 & 7.58 \\
\cline { 2 - 4 } & urban $>200,000-500,000$ & 2033 & 8.62 \\
\cline { 2 - 4 } & urban $>100,000-200,000$ & 1535 & 6.51 \\
\cline { 2 - 4 } & urban $>20,000-100,000$ & 4381 & 18.57 \\
\cline { 2 - 4 } & urban $\leq 20,000$ & 3093 & 13.11 \\
\cline { 2 - 4 } & rural & 45.62 \\
\hline
\end{tabular}


Table 1. Cont.

\begin{tabular}{|c|c|c|c|}
\hline Variable & Categories & $\mathbf{n}$ & $\%$ \\
\hline \multirow{7}{*}{ Occupational status } & employee & 8325 & 35.29 \\
\hline & self-employment or entrepreneur & 911 & 3.86 \\
\hline & farmer & 1515 & 6.42 \\
\hline & retired or on disability pension & 7853 & 33.29 \\
\hline & university or school student & 1537 & 6.51 \\
\hline & unemployed & 3332 & 14.12 \\
\hline & not provided & 120 & 0.51 \\
\hline \multirow{4}{*}{ Net income * } & $\leq 1000$ PLN & 5789 & 24.54 \\
\hline & $>1000$ to 2000 PLN & 8561 & 36.29 \\
\hline & $>2000$ PLN & 3799 & 16.10 \\
\hline & not provided & 5444 & 23.07 \\
\hline \multirow{4}{*}{ Marital status } & married & 14,422 & 61.13 \\
\hline & unmarried & 5530 & 23.44 \\
\hline & widower/widow & 2544 & 10.78 \\
\hline & divorced or separated & 1097 & 4.65 \\
\hline \multirow{2}{*}{$\begin{array}{l}\text { The use of health care services in } \\
\text { preceding } 12 \text { months }\end{array}$} & no use & 4297 & 18.21 \\
\hline & at least one episode of use & 19,296 & 81.79 \\
\hline \multirow{2}{*}{ Disability } & no & 20,228 & 85.74 \\
\hline & yes & 3365 & 14.26 \\
\hline \multirow{2}{*}{ Physical activity } & no & 15,525 & 65.80 \\
\hline & yes & 8068 & 34.20 \\
\hline \multirow{2}{*}{ Excessive use of alcohol } & no & 22,144 & 93.86 \\
\hline & yes & 1449 & 6.14 \\
\hline \multirow{4}{*}{ BMI } & $<18.50$ & 559 & 2.37 \\
\hline & $18.50-24.99$ & 10,080 & 42.72 \\
\hline & $25.00-29.99$ & 8823 & 37.40 \\
\hline & $>29.99$ & 4131 & 17.51 \\
\hline \multirow{2}{*}{ Smoking } & no & 17,392 & 73.72 \\
\hline & yes & 6201 & 26.28 \\
\hline \multirow{4}{*}{ Number of friends } & not more than 2 persons & 7660 & 32.47 \\
\hline & 3-4 persons & 4205 & 17.82 \\
\hline & 5-9 persons & 4874 & 20.66 \\
\hline & from 10 persons & 6293 & 26.67 \\
\hline \multirow{2}{*}{ Activities for local community } & no & 19,839 & 84.09 \\
\hline & yes & 3754 & 15.91 \\
\hline \multirow{2}{*}{ Membership of social organizations } & no & 20,850 & 88.37 \\
\hline & yes & 2743 & 11.63 \\
\hline \multirow{3}{*}{$\begin{array}{l}\text { Participation in religious meetings } \\
\text { monthly }\end{array}$} & 0 & 6939 & 29.41 \\
\hline & 1 & 2056 & 8.71 \\
\hline & $>1$ & 14,598 & 61.87 \\
\hline
\end{tabular}


Table 1. Cont.

\begin{tabular}{llll}
\hline Variable & Categories & $\mathbf{n}$ & $\mathbf{\%}$ \\
\hline \multirow{2}{*}{$\begin{array}{l}\text { Participation in the last election held } \\
\text { before the survey }\end{array}$} & no & 6957 & 29.49 \\
\cline { 2 - 4 } & yes & 16,027 & 67.93 \\
\cline { 2 - 4 } & not provided & 609 & 2.58 \\
\hline \multirow{2}{*}{$\begin{array}{l}\text { Declared political option } \\
\text { nomputer use }\end{array}$} & difficult to say & 9641 & 40.86 \\
\cline { 2 - 4 } & clear political sympathy & 3296 & 13.97 \\
\hline \multirow{2}{*}{$\begin{array}{l}\text { Mobile phone use } \\
\text { no }\end{array}$} & yes & 10,656 & 45.17 \\
\cline { 2 - 4 } & no & 11,005 & 46.65 \\
\cline { 2 - 4 } Daily TV viewing & yes & 12,588 & 53.35 \\
\hline & not watching TV & 4336 & 18.38 \\
\cline { 2 - 4 } & $<1$ h daily & 19,257 & 81.62 \\
\cline { 2 - 4 } & $1-2$ h daily & 604 & 2.56 \\
\cline { 2 - 4 } Perception of effectiveness of social & $>2$ h daily & 2297 & 9.74 \\
\cline { 2 - 4 } & ineffective or undecided & 6937 & 29.40 \\
\cline { 2 - 4 } & effective & 13,755 & 58.30 \\
\hline
\end{tabular}

\footnotetext{
${ }^{a}$ education categories used in the survey were mapped by the levels distinguished by the International Standard Classification of Education (ISCED) classification from 2011 [25]. * In 2011, according to the Polish National Bank, the 1 USD to PLN exchange rate ranged between 2.9822 and 3.4174 and the mean gross salary in Poland was 3400 PLN.
}

\subsection{Predictors of the Opinion about the Effectiveness of Social Campaigns}

Multivariate logistic regression modelling was performed for 22 variables deemed to have impact on the opinion of respondents about the effectiveness of health-related social campaigns (Table 2). The model demonstrated adequate goodness-of-fit (Hosmer and Lemeshow test $\mathrm{chi}^{2}=14.02, \mathrm{df}=8$, $p=0.081$ ). However, overall, the predicting value of the model was rather limited (the increase of proper classification from $53.4 \%$ to $58.7 \%$; Nagelkerke $R^{2}=0.052$ ).

Table 2. Multivariate logistic regression results for opinion about the effectiveness of health-related social campaigns.

\begin{tabular}{lllll}
\hline Variable & Categories & OR & 95\%CI & $p$ \\
\hline Gender & female/male & 0.88 & $0.83-0.93$ & 0.000 \\
\hline & $18-24$ & & & 0.000 \\
& $25-34$ & 1.18 & $1.04-1.34$ & 0.009 \\
Age category & $35-44$ & 1.15 & $1.00-1.32$ & 0.055 \\
& $45-54$ & 0.99 & $0.86-1.15$ & 0.935 \\
& $55-64$ & 0.90 & $0.77-1.06$ & 0.199 \\
& $>64$ & 0.99 & $0.82-1.19$ & 0.875 \\
\hline \multirow{4}{*}{ Education level } & primary education & & 0.000 \\
& lower secondary education & 1.11 & $1.02-1.22$ & 0.023 \\
& upper secondary education & 1.28 & $1.16-1.41$ & 0.000 \\
& post-secondary non-tertiary education or higher level & 1.39 & $1.24-1.56$ & 0.000 \\
\hline & urban $>500,000$ & & & 0.000 \\
Place of residence & urban $>200,000-500,000$ & 0.96 & $0.86-1.08$ & 0.523 \\
& urban $>100,000-200,000$ & 0.89 & $0.79-1.01$ & 0.063 \\
& urban $>20,000-100,000$ & 0.99 & $0.89-1.09$ & 0.756 \\
& urban $\leq 20,000$ & 0.84 & $0.76-0.94$ & 0.002 \\
& rural & 0.79 & $0.72-0.87$ & 0.000 \\
\hline
\end{tabular}


Table 2. Cont.

\begin{tabular}{|c|c|c|c|c|}
\hline Variable & Categories & OR & $95 \% \mathrm{CI}$ & $p$ \\
\hline \multirow{7}{*}{ Occupational status } & employee & & & 0.004 \\
\hline & self-employment or entrepreneur & 1.03 & $0.91-1.18$ & 0.618 \\
\hline & farmer & 1.18 & $1.03-1.34$ & 0.016 \\
\hline & retired or on disability pension & 1.07 & $0.96-1.20$ & 0.196 \\
\hline & university or school student & 1.16 & $1.00-1.34$ & 0.057 \\
\hline & unemployed & 0.93 & $0.84-1.02$ & 0.131 \\
\hline & not provided & 1.15 & $0.77-1.72$ & 0.496 \\
\hline \multirow{4}{*}{ Net income } & $\leq 1000$ PLN & & & 0.015 \\
\hline & $>1000$ to 2000 PLN & 1.05 & $0.97-1.14$ & 0.197 \\
\hline & >2000 PLN & 1.11 & $1.01-1.23$ & 0.029 \\
\hline & not provided & 0.95 & $0.87-1.04$ & 0.247 \\
\hline \multirow{4}{*}{ Marital status } & married & & & 0.001 \\
\hline & unmarried & 0.88 & $0.81-0.96$ & 0.004 \\
\hline & widower/widow & 0.89 & $0.80-0.98$ & 0.023 \\
\hline & divorced or separated & 0.86 & $0.76-0.97$ & 0.018 \\
\hline $\begin{array}{l}\text { The use of health care services } \\
\text { in preceding } 12 \text { months }\end{array}$ & no use/at least one episode of use & 0.97 & $0.90-1.04$ & 0.339 \\
\hline Disability & no/yes & 0.94 & $0.86-1.03$ & 0.170 \\
\hline Physical activity & no/yes & 1.14 & $1.07-1.21$ & 0.000 \\
\hline Excessive use of alcohol & no/yes & 0.84 & $0.76-0.93$ & 0.001 \\
\hline \multirow{4}{*}{ BMI } & $18.50-24.99$ & & & 0.113 \\
\hline & $<18.50$ & 0.89 & $0.75-1.05$ & 0.165 \\
\hline & $25.00-29.99$ & 1.00 & $0.94-1.07$ & 0.888 \\
\hline & $>29.99$ & 0.93 & $0.86-1.01$ & 0.073 \\
\hline Smoking & no/yes & 0.88 & $0.83-0.94$ & 0.000 \\
\hline \multirow{5}{*}{ Number of friends } & not more than 2 persons & & & 0.020 \\
\hline & 3-4 persons & 1.14 & $1.05-1.23$ & 0.002 \\
\hline & 5-9 persons & 1.09 & $1.01-1.17$ & 0.029 \\
\hline & from 10 persons & 1.08 & $1.01-1.17$ & 0.030 \\
\hline & not provided & 1.01 & $0.86-1.20$ & 0.878 \\
\hline Activities for local community & no/yes & 1.08 & $1.00-1.17$ & 0.053 \\
\hline $\begin{array}{l}\text { Membership of social } \\
\text { organizations }\end{array}$ & no/yes & 1.10 & $1.01-1.20$ & 0.028 \\
\hline \multirow{3}{*}{$\begin{array}{l}\text { Participation in religious } \\
\text { meetings monthly }\end{array}$} & 0 & & & 0.000 \\
\hline & 1 & 1.17 & $1.06-1.30$ & 0.002 \\
\hline & $>1$ & 1.13 & $1.06-1.20$ & 0.000 \\
\hline \multirow{3}{*}{$\begin{array}{l}\text { Participation in the last } \\
\text { election held before the survey }\end{array}$} & no & & & 0.000 \\
\hline & yes & 1.21 & $1.14-1.29$ & 0.000 \\
\hline & not provided & 1.07 & $0.91-1.28$ & 0.398 \\
\hline \multirow{3}{*}{ Declared political option } & no political declarations & & & 0.000 \\
\hline & don't know & 1.02 & $0.95-1.11$ & 0.560 \\
\hline & clear political declaration & 1.41 & $1.33-1.49$ & 0.000 \\
\hline Computer use & no/yes & 1.00 & $0.93-1.08$ & 0.982 \\
\hline Mobile phone & no/yes & 1.17 & $1.07-1.28$ & 0.001 \\
\hline \multirow{4}{*}{ Daily TV viewing } & not watching TV & & & 0.004 \\
\hline & $<1$ h daily & 1.14 & $0.97-1.35$ & 0.109 \\
\hline & 1-2 h daily & 1.27 & $1.09-1.48$ & 0.002 \\
\hline & $>2 \mathrm{~h}$ daily & 1.19 & $1.03-1.39$ & 0.020 \\
\hline Constant & & 0.53 & & 0.000 \\
\hline
\end{tabular}




\subsection{Sociodemographic Determinants}

Men were more skeptical about the effectiveness of social campaigns (OR $0.88,95 \% \mathrm{CI}=1.04-1.33$ ) than women. As far as age groups, a significant difference was found only for comparison of the youngest group of respondents (18-24) and those in the category of 25-34 years of age (OR 0.88, $95 \% \mathrm{CI}=1.04-1.34)$. There were no significant differences between the referential category (18-24) and older age categories. The respondents who achieved higher levels of education were more prone to believe in the effectiveness of health-related social campaigns. The odds that a person with post-secondary or higher education is convinced about their effectiveness were 1.40 times higher than a person with primary education. Respondents living in urban areas (OR $0.89,95 \% \mathrm{CI}=0.72-0.87$ ) and small cities $<20,000$ inhabitants (OR $0.84,95 \% \mathrm{CI}=0.76-0.94$ ) were less prone to express belief in the effectiveness of campaigns than those living in urban areas with $>500,000$ inhabitants. Persons with net income surpassing 2000 PLN were more often convinced about campaigns effectiveness than persons having a net income not surpassing 1000 PLN (OR 1.11; 95\% CI $=1.01-1.23)$. Finally, married persons demonstrated a higher belief in the effectiveness of campaigns than unmarried (OR 0.88 , $95 \% \mathrm{CI}=0.81-0.96$ ), widows / widowers (OR 0.89, 95\% CI $=0.80-0.98)$, and divorced or in separation (OR $0.86,95 \%$ CI $=0.76-0.97)$.

\subsection{Lifestyle and Health Status}

The opinion about effectiveness of health-related campaigns did not depend on disability status, the use of health care services during the preceding year or BMI. Persons declaring at least some form of physical activity were more prone to believe in campaign's effectiveness ( OR 1.40, 95\% CI $=1.07-1.21$ ). Smokers and persons drinking alcohol excessively less frequently showed belief in campaign's effectiveness (respectively, $\mathrm{OR}=0.88,95 \% \mathrm{CI}=0.83-0.94$, and $\mathrm{OR}=0.84$, and $95 \% \mathrm{CI}=0.76-0.93$ ).

\subsection{TV and IT Use}

There was no difference between computer users and nonusers (OR 1.00, 95\% CI $=0.93-1.08$ ). Mobile phone users were more prone to believe in campaign's effectiveness (OR 1.17, $95 \% \mathrm{CI}=1.07-1.28)$. The odds that person watching TV will be convinced about the effectiveness of social campaigns was at least 1.14 times higher than person not watching TV at all. The highest difference was seen between non-watchers and persons watching TV for 1-2 h daily (OR 1.27, $95 \%$ CI $=1.09-1.48)$.

\subsection{Social Participation}

All but one variable related to social participation had a statistically significant influence on the opinion about the effectiveness of health campaigns. The comparison of persons who either undertake or do not undertake activities for local community did not show a statistically significant difference $(p=0.53, \mathrm{OR}=1.08,95 \% \mathrm{CI}=1.00-1.17)$.

Respondents with a higher number of friends with whom regular meetings or contacts were maintained, more frequently believed in the effectiveness of health campaigns. Results for comparisons between persons with not more than two friends were (OR (95\% CI)), for 3-4 friends, $1.14(1.05-1.23)$, for 5-9 friends, 1.09 (1.01-1.18), and for more than 9 friends, 1.08 (1.01-1.17).

Furthermore, the odds that a person who declared membership to at least one social organization were $1.10(95 \% \mathrm{CI}=1.01-1.20)$ times higher when compared with a person who did not belong to such organizations. The conviction about the effectiveness of social campaigns was also higher among respondents who participated in elections of local governments $(\mathrm{OR}=1.21,95 \% \mathrm{CI}=1.14-1.29)$ and who could indicate a political party which would be the closest to their views $(\mathrm{OR}=1.41$; $95 \% \mathrm{CI}=1.33-1.49)$. 
Persons attending religious services or meetings once or twice monthly more frequently believed in the effectiveness than those not practicing or practicing less frequently than once monthly (OR and $95 \% \mathrm{CI}$, respectively; $1.17,1.06-1.30$, and $1.13,1.06-1.20$ ).

\section{Discussion}

The analysis performed in this paper was based on the large dataset retrieved from the 2011 wave of nationwide Social Diagnosis study. Among the respondents, about 53\% were convinced that health-related campaigns are effective. After exclusion of cases with at least one missing value, a multivariate logistic regression model was developed with 23,593 cases. The independent variables used in the model represented four main groups. They included socio-demographic and economic variables, health care utilization and lifestyle, TV and IT use, and finally, social participation. Only four of the independent variables did not exert any influence on the opinion about effectiveness of health-related social campaigns. The level of influence of independent variables that reached statistical significance was not high. The differences between reference categories and tested categories expressed as OR, rarely reached values below 0.80 or above 1.20 . The highest differences were seen for the comparison of persons without political sympathies and those with a clear connection with their closest political party $(\mathrm{OR}=1.41)$, for persons who did not participate and those who participated in the last election $(\mathrm{OR}=1.21)$, for persons with the lowest and the highest level of education $(\mathrm{OR}=1.39)$, or those with upper secondary education $(\mathrm{OR}=1.28)$, and finally for the comparison of persons not watching TV at all with those watching it for $1-2 \mathrm{~h}$ daily $(\mathrm{OR}=1.27)$.

The people more frequently convinced of the effectiveness of social campaigns, considering sociodemographic characteristics, are women, the persons who reached a higher education level, those living in larger urban areas, persons employed in private or public organizations, people with the highest income, and those living as married couples.

Utilization of health care services during the previous year and disability status did not have a significant impact on the opinion about such effectiveness. It is surprising that utilization of health care services did not have an impact on the opinion about health campaigns. One might expect that persons having more intensive contact with health care systems would also receive some advice on general health risks and therefore should appreciate the importance of health promotion interventions on a societal level. Persons who smoked or declared excessive alcohol drinking expressed a belief about campaign's effectiveness less frequently. Such an effect was not seen in case of persons with obesity or who were overweight.

Computer usage also did not predict an opinion about the effectiveness of health campaigns. This finding seems to remain in line with the results of the study reported by Redmond et al. [26]. The analysis of the data from Health Information National Trends Survey carried out in the USA in 2005 and 2007, revealed that the use of print media and interpersonal sources of health information exerted a stronger effect on self-reported health behaviors than the use of other sources, including TV and the Internet.

On the other hand, the model developed in our study showed that persons who watched TV at least one hour daily were more in favor of the effectiveness of health campaigns than those who did not watch TV at all. A similar effect was seen among those who used a mobile phone.

Those who were involved in religious participation, engaged in social organizations, had defined political views and declared participation in voting in local government elections preceding the Social Diagnosis study favored the effectiveness of social campaigns.

Unfortunately, it seems that there is a research gap as to the perception of social campaigns by the general public. It is also obvious that more efforts are directed toward the assessment of the needs of potential target groups for specific campaigns. Therefore, a discussion of the results obtained in this study in comparison to other populations is hardly possible. However, opinion about the effectiveness of health-related social campaigns may be treated as an indicator of attitude to public health measures and readiness to accept such communications on key health problems in the society. Assuming this 
understanding, one can refer to the effects reported of social participation variables used in our study on health behaviors and related outcomes.

The findings reported by other authors tend to agree with the results of our study. Bender et al. demonstrated that higher social capital was associated with a higher probability of participating in a health check-up [27]. In their study, informal socializing and voter turnout was used as measures of social capital. The effect of informal socializing was maintained after inclusion of neighborhood deprivation in the model, and voting turnout became non-significant. Informal socializing was assessed based on responses to two items asking about frequency of contacts with family members and with friends or acquaintances. Neighborhood (census districts) voter turnout was based on the neighborhood participation in the Danish parliament election [27]. Inequality in voter participation may be related to self-rated health. According to Blakely et al., individuals living in the states (USA) with the highest voting inequality had an odds ratio of fair/poor self-rated health status of 1.43 ( $95 \%$ CI: 1.22-1.68) [28].

The beneficial influence of involvement in religious participation/practices on health outcomes, morbidity, adult mortality risk, and longevity was reported earlier [29-31]. This effect is attributed to the impact of religious involvement on lifestyle factors and social behaviors [29,32-34]. Some authors also emphasize the importance of social support which can be received in religious communities [29,32-35]. The impact of involvement in religious practices on the perception of the effectiveness of health-related social campaigns seen in our study may be linked to an acceptant attitude toward society level communications encouraging healthy behaviors related to religious involvement.

Interestingly, people demonstrating harmful health-related behaviors are less prone to participate in social activities, e.g., in elections. In the study of Albright et al., daily smokers were less than half as likely as non-smokers to report having voted in the election [36]. The authors suggested that their findings could indicate that there was a link between risky health behaviors and political mistrust. In our study, smokers were also less likely to believe in the effectiveness of social campaigns. It seems that this mistrust may be extended to other domains. It is also important to note, that, although smokers are a key target group for antismoking campaigns, they may be more resistant to this form of health communication than non-smokers.

The number of close friends is treated as one of the indicators of social support. It is commonly accepted that loneliness leads to unfavorable health outcomes and social support is linked to better health, partly because it prevents loneliness $[37,38]$. Our study revealed that persons with a higher number of friends were more prone to believe in the effectiveness of social campaigns. It is likely that the protective health effect of social support may to some extent be explained by an increase of an acceptant attitude linked to social interaction by health promotion interventions.

\subsection{Limitations}

The study reported in this paper suffers from several limitations. First, it is a secondary analysis of data collected during a study which was not focused on the analysis of determinants of societal approaches to social campaigns. Second, the selection of the variables used as predictors for logistic regression modelling was based on the assumption that they may have an impact on respondents' views about the effectiveness of campaigns. The Social Diagnosis study encompassed only one item related to social campaigns and a more thorough analysis of relations between respondents' views and variables established based on the items available in the individual questionnaire was not possible. Among the most important deficiencies, one should enlist the lack of feedback on understanding and being able to properly identify examples of health-related social campaigns. Therefore, it is not fully clear if the selection of the responses showing the lack of belief in the effectiveness of campaigns or inability to express an opinion originates from problems with understanding the concept of social campaigns or an actual opinion about their effectiveness. This weakness was compensated to some degree by the way the item asking about social campaigns was formulated. Two examples of social campaigns were included in the content of the item when asking about their effectiveness. 
Finally, the dataset available from each wave of the Social Diagnosis study is very broad and some potentially relevant items could have been overlooked as to their importance for the opinion about social campaigns.

\section{Conclusions}

The perception of the effectiveness of social campaigns by the general public has rarely been addressed so far. It is also not clear how such perception translates into the effectiveness of campaigns measured with health-related outcomes, e.g., actual change of harmful behaviors.

The analysis performed in this paper indicates that the highest conviction about effectiveness of social campaigns was demonstrated by females, persons with higher education and achieving higher income, remaining in marital relation and living in more urbanized areas. Unhealthy behaviors declared by the respondents (higher alcohol consumption, and tobacco smoking) were related to lower belief in the effectiveness of social campaigns. It is not clear if such attitude precedes the beginning of risky behaviors, or it is developed in association with such behaviors. Nonetheless, it seems that people undertaking risky behaviors could be less prone to accept public communication related to health challenges. On the other hand, respondents presenting healthier lifestyles, as confirmed by involvement in physical activities, showed more positive attitudes towards campaigns.

Interestingly, the factors related to social participation which favor the conviction about social campaigns being effective, are also associated with beneficial health effects. This was seen in both the case of election participation and involvement in religious practices.

The finding that recent utilization of health care services does not influence opinions about the campaigns' effectiveness is unexpected. One could expect that personal experience of searching for medical help would result in a more open attitude toward health-related communication present in the public domain.

Funding: The study was performed in the framework of statutory project No K/ZDS/006112 carried out in the Department of Health Promotion, Institute of Public Health, Faculty of Health Sciences, Jagiellonian University Medical College, Kraków, Poland.

Acknowledgments: The author would like to thank Alex Solsbery, MA, for proofreading of the manuscript.

Conflicts of Interest: The author declares no conflict of interest.

\section{References}

1. Kotler, P.; Zaltman, G. Social marketing: An approach to planned social change. J. Mark. 1971, 35, 3-12. [CrossRef] [PubMed]

2. Andreasen, AR. Marketing Social Change: Changing Behaviour to Promote Health, Social Development, and the Environment; Josey-Bass: San Francisco, CA, USA, 1995.

3. MacFadyen, L.; Stead, M.; Hastings, G.B. Social marketing. In The Marketing Book, 5th ed.; Baker, M.J., Ed.; Butterworth Heinemann: Oxford, UK, 2003.

4. McDermott, L.; Stead, M.; Hastings, G. What is and what is not social marketing: The challenge of reviewing the evidence. J. Mark. Manag. 2005, 21, 545-553. [CrossRef]

5. Andreasen, A.R. Marketing social marketing in the social change marketplace. J. Public Policy Mark. 2002, 21, 3-13. [CrossRef]

6. World Health Organization (WHO). Global Health Risks: Mortality and Burden of Disease Attributable to Selected Major Risks; World Health Organization: Geneva, Switzeland, 2009. Available online: http:/ / www.who.int/ healthinfo/global_burden_disease/GlobalHealthRisks_report_full.pdf. (accessed on 24 November 2018).

7. Glanz, K.; Bishop, D.B. The role of behavioral science theory in development and implementation of public health interventions. Annu. Rev. Public Health 2010, 31, 339-418. [CrossRef] [PubMed]

8. Bouton, M.E. Why behavior change is difficult to sustain. Prev. Med. 2014, 68, 29-36. [CrossRef] [PubMed]

9. Kelly, M.P.; Barker, M. Why is changing health-related behavior so difficult? Public Health 2016, 136, 109-116. [CrossRef] [PubMed] 
10. Marteau, T.M.; Holland, G.J.; Kelly, M.P. Changing population behavior and reducing health disparities: Exploring the potential of "choice architecture" interventions. In Emerging Behavioural and Social Science Perspectives on Population Health; Kaplan, R.M., Spittel, M., David, D.H., Eds.; National Institutes of Health/Agency for Healthcare Research and Quality: Bethesda, MD, USA, 2015.

11. Moodie, R.; Stuckler, D.; Monteiro, C.; Sheron, N.; Neal, B.; Thamarangsi, T.; Lincoln, P.; Casswell, S. On behalf The Lancet NCD Action Group. Profits and pandemics: Prevention of harmful effects of tobacco, alcohol, and ultra-processed food and drink industries. Lancet 2013, 381, 670-679. [CrossRef]

12. Aceves-Martins, M.; Llauradó, E.; Tarro, L.; Moreno-García, CF.; Escobar, T.G.T.; Solà, R.; Giralt, M. Effectiveness of social marketing strategies to reduce youth obesity in European school-based interventions: A systematic review and meta-analysis. Nutr. Rev. 2016, 74, 337-351. [CrossRef] [PubMed]

13. Xia, Y.; Deshpande, S.; Bonates, T. Effectiveness of social marketing interventions to promote physical activity among adults: A systematic review. J. Phys. Act. Health 2016, 13, 1263-1274. [CrossRef] [PubMed]

14. Firestone, R.; Rowe, C.J.; Modi, S.N.; Sievers, D. The effectiveness of social marketing in global health: A systematic review. Health Policy Plann. 2016, 32, 110-124. [CrossRef] [PubMed]

15. Friedman, A.L.; Kachur, R.E.; Noar, SM.; McFarlane, M. Health communication and social marketing campaigns for sexually transmitted disease prevention and control: What is the evidence of their effectiveness? Sex Transm. Dis. 2016, 43 (2 Suppl. 1), S83-S101. [CrossRef]

16. Robinson, MN.; Tansil, K.A.; Elder, R.W.; Soler, R.E.; Labre, M.P.; Mercer, S.L.; Eroglu, D.; Baur, C.; Fridinger, F.; Green, L.W.; et al. Community preventive services task force. Mass media health communication campaigns combined with health-related product distribution: A community guide systematic review. Am. J. Prev. Med. 2014, 47, 360-371. [CrossRef] [PubMed]

17. MacDonald, L.; Cairns, G.; Angus, K.; de Andrade, M. Promotional communications for influenza vaccination: A systematic review. J Health Commun. 2013, 18, 1523-1549. [CrossRef] [PubMed]

18. Cairns, J.E.; Rundle-Thiele, S.R. Eating for the better: A social marketing review (2000-2012). Public Health Nutr. 2014, 17, 1628-1639. [CrossRef] [PubMed]

19. Bala, M.; Strzeszynski, L.; Cahill, K. Mass media interventions for smoking cessation in adults. Cochrane Database Syst. Rev. 2008, 23, CD004704.

20. Janssen, M.M.; Mathijssen, J.J.P.; van Bon-Martens, M.J.H.; van Oers, H.A.M.; Garretsen, H.F.L. Effectiveness of alcohol prevention interventions based on the principles of social marketing: A systematic review. Subst. Abuse Treat. 2013, 8, 18. [CrossRef] [PubMed]

21. McAfee, T.; Davis, K.C.; Alexander, R.L.; Pechacek, T.F.; Bunnell, R. Effect of the first federally funded US antismoking national media campaign. Lancet 2013, 382, 2003-2011. [CrossRef]

22. Social Diagnosis 2000-2013. Objective and Subjective Quality of Life in Poland. 2011. Available online: http:/ / www.diagnoza.com/index-en.html (accessed on 20 November 2018).

23. Social Diagnosis. Integrated database. Available online: http://www.diagnoza.com/ (accessed on 17 November 2016).

24. Panek, T.; Czapinski, J.; Kotowska, I.E. The research method. In Social Diagnosis 2011. Objective and Subjective Quality of Life in Poland; Czapinski, J., Panek, T., Eds.; Contemporary Economics, Quarterly of University of Finance and Management in Warsaw: Warsaw, Poland, 2011; Volume 5, pp. 40-49.

25. United Nations Educational, Scientific and Cultural Organization (UNESCO) Institute for Statistics (2012). International Standard Classification of Education (ISCED). Montreal, QC, Canada, 2011. Available online: http:/ / www.uis.unesco.org/Education/Documents/isced-2011-en.pdf (accessed on 15 January 2018).

26. Redmond, N.; Baer, H.J.; Clark, C.R.; Lipsitz, S.; Hicks, L.S. Sources of health information related to preventive health behaviors in a national study. Am. J. Prev. Med. 2010, 38, 620-627. [CrossRef] [PubMed]

27. Bender, A.M.; Kawachi, I.; Jorgensen, T.; Pisigner, C. Neighborhood social capital is associated with participation in health checks of a general population: A multilevel analysis of a population-based lifestyle intervention-The Inter99 study. BMC Public Health 2015, 15, 694. [CrossRef] [PubMed]

28. Blakely, T.A.; Kennedy, B.P.; Kawachi, I. Socioeconomic inequality in voting participation and self-rated health. Am. J. Public Health 2001, 91, 99-104. [PubMed]

29. Levin, J. Religion and health. Is there an association, is it valid and is it casual? Soc. Sci. Med. 2014, 38, 1475-1482. [CrossRef]

30. Levin, J. Religion and physical health among older Israeli Jews: Findings from the SHARE-Israel study. Israel Med. Assoc. J. 2012, 14, 595-601. 
31. Hummer, R.A.; Ellison, C.G.; Rogers, R.G.; Moulton, B.E.; Romero, R.R. Religious involvement and adult mortality in the United States: Review and perspective. South Med. J. 2004, 97, 1223-1230. [CrossRef] [PubMed]

32. Jarvis, G.K.; Northcott, H.C. Religion and differences in morbidity and mortality. Soc. Sci. Med. 1987, 25, 813-824. [CrossRef]

33. Iannaccone, L.; Stark, R.; Finke, R. Rationality and the "religious mind". Econ. Inq. 1998, 36, 373-389. [CrossRef]

34. Trust-based prayer expectancies and health among older Mexican Americans. J. Relig. Health. 2014, 53, 591-603.

35. Hayward, R.D.; Krause, N. Religion, mental health and well-being: Social aspects. In Religion, Personality, and Social Behavior; Saroglou, V., Ed.; Psychology Press: New York, NY, USA, 2014; pp. 255-280.

36. Albright, K.; Hood, N.; Ma, M.; Levinson, A.H. Smoking and (not) voting: The negative relationship between a health-risk behavior and political participation in Colorado. Nicot. Tob. Res. 2016, 18, 371-376. [CrossRef] [PubMed]

37. Cacioppo, J.T.; Hawkley, L.C.; Crawford, E.; Ernst, J.M.; Burleson, M.H.; Kowalewski, R.B.; Malarkey, W.B.; Van Cauter, E.; Berntson, G.G. Loneliness and health: Potential mechanisms. Psychosom. Med. 2002, 64, 407-417. [CrossRef] [PubMed]

38. Hawkley, L.C.; Masi, C.M.; Berry, J.D.; Cacioppo, J.T. Loneliness is a unique predictor of age-related differences in systolic blood pressure. Psychol. Aging 2006, 21, 152-164. [CrossRef] [PubMed]

(C) 2019 by the author. Licensee MDPI, Basel, Switzerland. This article is an open access article distributed under the terms and conditions of the Creative Commons Attribution (CC BY) license (http:/ / creativecommons.org/licenses/by/4.0/). 